\title{
Does attending an advanced life support course as a final year medical student improve key non-technical skills during CPR?
}

\author{
Dr Jonathan Taylor Simulation Fellow ${ }^{1}$, Dr Simon Mercer, Clinical Director ${ }^{1}$, Consultant Anaesthetist ${ }^{2}$ \\ ${ }^{1}$ Centre for Simulation and Patient Safety, UK \\ ${ }^{2}$ Aintree University Hospital, Liverpool, UK
}

\section{Background and Goals}

Advanced Life Support (ALS) aims to teach the provision of standardised and evidence based resuscitation algorithms. It also states one of its specific learning outcomes as "[to] utilise non-technical skills (NTS) to facilitate strong team leadership and effective team membership."[1] Our centre provides a multi-disciplinary fully-immersive simulation course for final year medical and nursing students. We defined key performance indicators (KPIs) during resuscitation of a cardiac arrest, which directly relate to team resource management and observed the impact of attending an ALS Course.
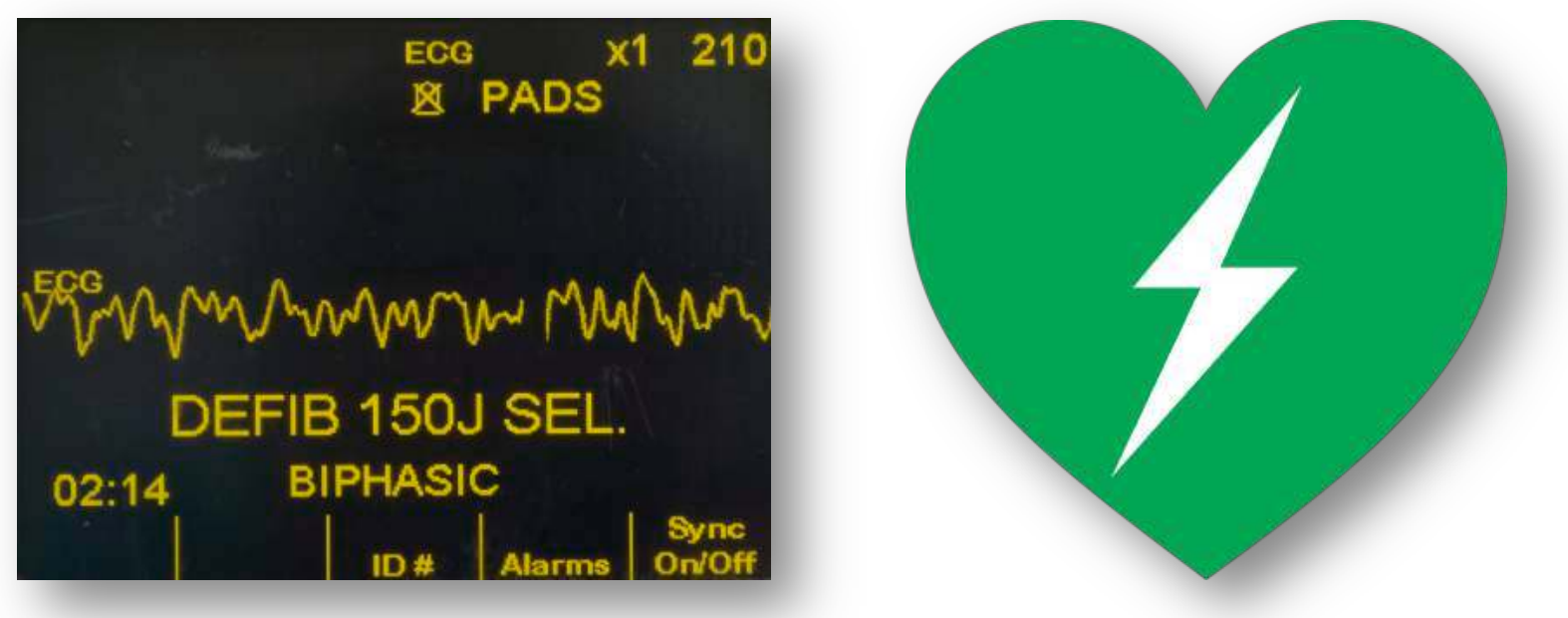

\section{Materials and methods}

A video analysis of 19 identical cardiac arrest scenarios was performed. Students had recently attended an ALS course in half of these scenarios. The KPIs selected echoed two major principles taught on ALS. To minimise interruptions in chest compressions, and early defibrillation of a shockable rhythm. A return of spontaneous circulation was simulated following the delivery of two simulated shocks by a confederate.

Statistical analysis of the timings was carried about using the Mann Whitney U Test. Fischers Exact test was used to analyse the effect of ALS on team leadership.

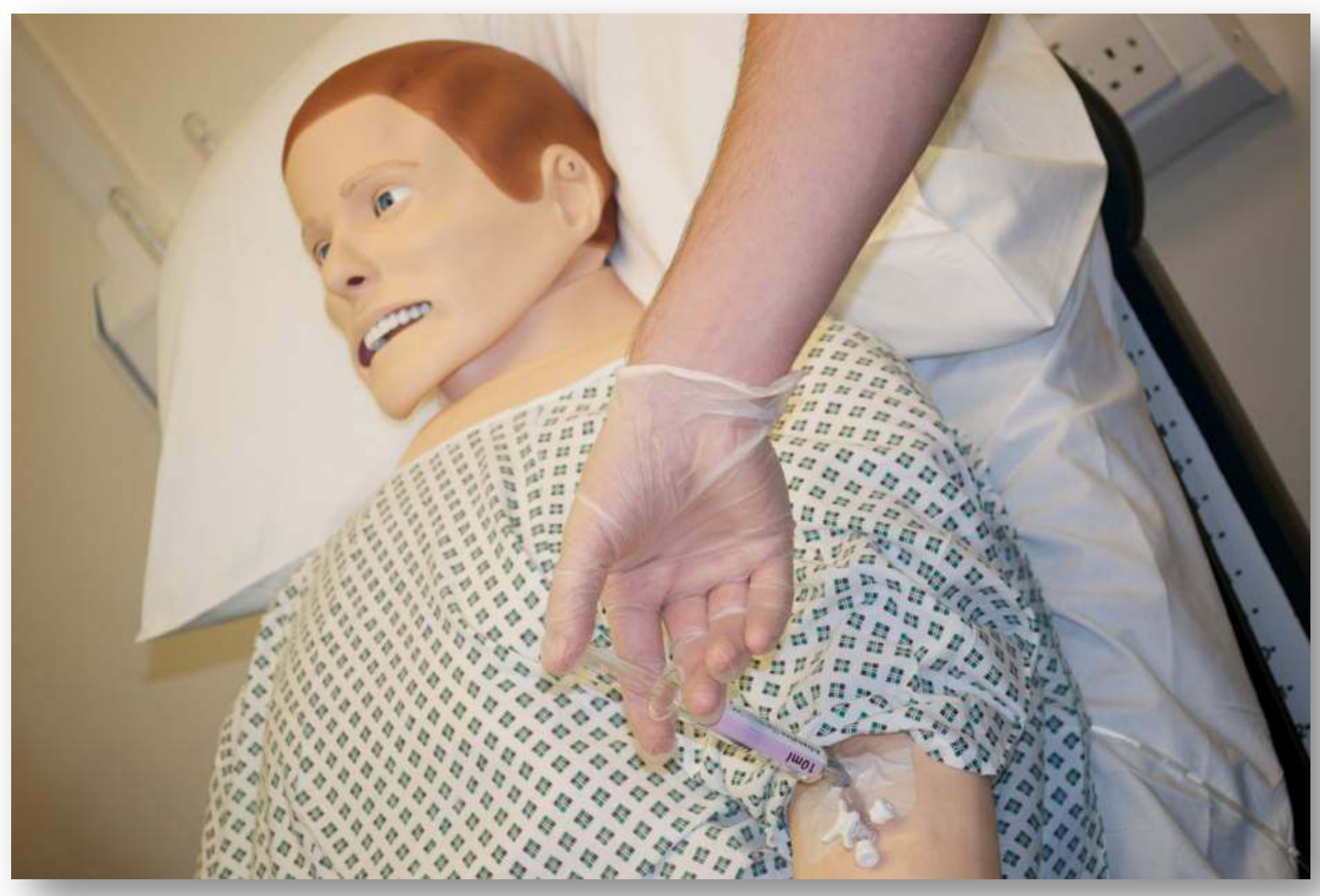

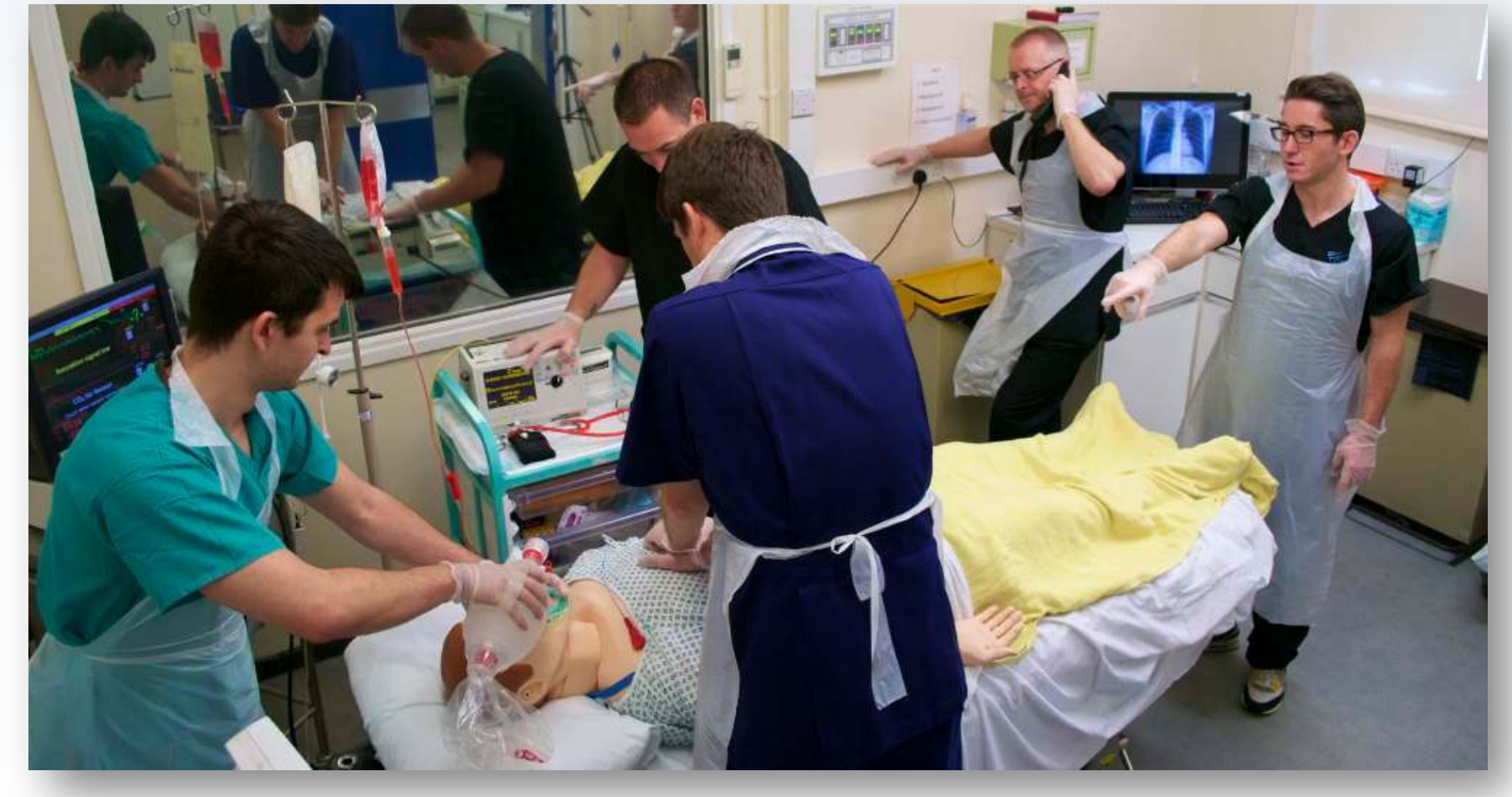

\section{Results}

\begin{tabular}{lccc}
\hline \multicolumn{1}{c}{$\begin{array}{c}\text { Key Performance } \\
\text { Indicator }\end{array}$} & Attended ALS ( $\mathbf{n = 1 0 )}$ & Not Attended ALS ( $\mathbf{n = 9 )}$ & P Values \\
\hline $\begin{array}{l}\text { Recognition of cardiac } \\
\text { arrest to starting CPR. }\end{array}$ & 11 seconds & 8 seconds & 0.90448 \\
$\begin{array}{l}\text { Recognition of cardiac } \\
\text { arrest to defibrillator } \\
\text { attached and turned on. }\end{array}$ & 56 seconds & 69 seconds & 0.79468 \\
$\begin{array}{l}\text { Recognition of VF to first } \\
\text { shock. }\end{array}$ & 32 seconds & 42 seconds & 0.87288 \\
$\begin{array}{l}\text { Time off chest. } \\
\begin{array}{l}\text { Was there a clear hands } \\
\text { off leader? (\%) }\end{array}\end{array} \quad 64$ seconds & 68 seconds & 0.25014 \\
\hline
\end{tabular}

\section{Conclusion}

In order to maintain situational awareness, it is important that the leader of the cardiac arrest team is devolved of technical tasks such as CPR. We demonstrated in this short audit project that attendance at an ALS course has no statistically significant effect $(p=0.05)$ on any of the timings that we measured. Those candidates who had attended an ALS course, were far less likely to act as a "hands off leader" during the scenario (significant at $P=0.05$ ) and so were at increased risk of losing their situational awareness by becoming task focused. We recommend that the resuscitation council put more of an emphasis on the important non-technical skill of leadership and incorporate this into their scenarios.

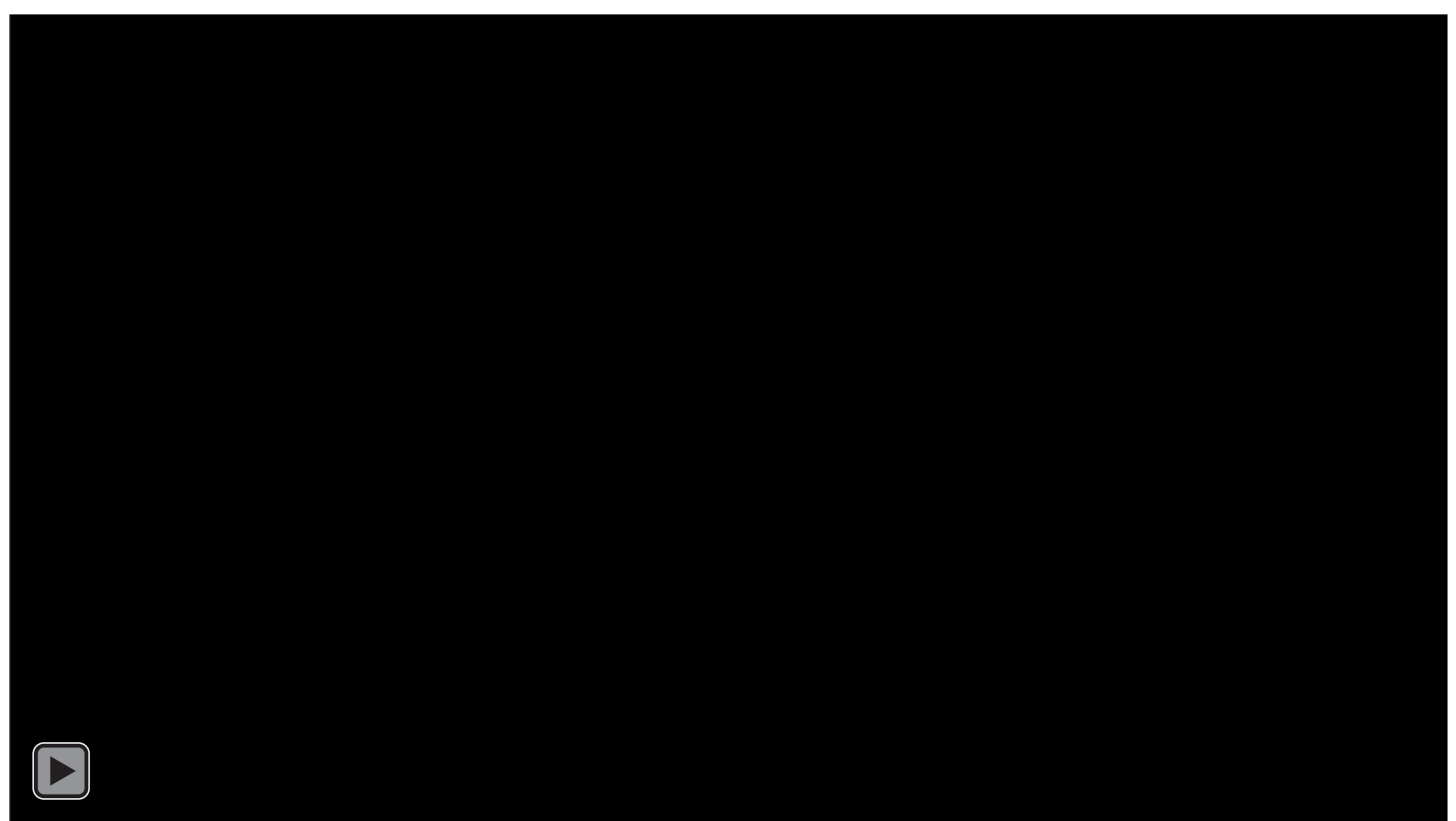

References

[1] https://www.resus.org.uk/information-on-courses/advanced-life-support/ Accessed 3 $3^{\text {rd }}$ December 2015 